\title{
Documentation Thoughts
}

\author{
Ruth Devine* \\ President Devine \& Associates, Inc, Washington State, USA
}

${ }^{*}$ Correspondence Author: Dr. Ruth Devine, President Devine \& Associates, Inc, Washington State, USA, Tel: +1 2062299796; E-mail: Ruth@Ruthdevine.com

Received: October 30, 2018; Accepted: November 08, 2018; Published: November 08, 2018;

The rules and legality of documentation do not change despite writing styles and delivery mode of documents.

Each profession has their own language and their own acronyms. Often the lingo obscures the actual documentation. I believe there is a false sense that the complex verbiage somehow indicates a level of competency that the non-professional may perceive as skilled. One remedy many organizations use is a template. While documentation conformity increases, detailed and "additional information" documentation in addition to the template requirements may be missing and the resulting recorded information may be subject to misinterpretation. Think of some of the surveys you have completed; do they seem to lead you down a predetermined and limited path?

I have edited reports, reviewed cases, medical reviews and cost containment documentation for more than 2 decades. My first suggestion for better documentation is to determine your audience. Who is reading the documentation? Are you writing or documenting for the CEO of an insurance company or the insurance commissioner? Would your documentation be different? Then ask yourself why. In our organization, I always ask if the case management report will be relevant in $2-5$ years. Will your decision process and those corresponding events be adequately described in your report? I like reports that can stand alone, reports not dependent on the previous reporting. This may be a personal professional preference.

Are you documenting that certain tasks have been completed? Have you done your due diligence? Staying within your scope of practice or license when documenting should always be foremost when writing and editing.

Where is the report (report, form or template) to be used? I am referring to the institutional, more codified venues such as hospitals, financial institutions, and transportation, insurance, engineering and legal professions.

Many organizations have developed documentation methods for decision making that are exact to their standards.

Those of us who develop documentation tools, forms and guidelines most likely have access to the specific who, what, why and where questions and the form the answers need to take. Professional standards are always implied in documentation guidelines and tools. In developing the document standards, always check on the complexity of what is needed. I refer back to answer the question, who is the intended audience?
I have been at times the person to fill in forms and document or decipher what is being asked in cases where the documentation limitations would have led me to non-compliance or confusion. I'll admit it, I just did not do it. The result was "no documentation" or delayed reporting. Humans and water always fall into the line of least resistance. When I knew exactly what was needed, knew upfront who was reading my document and had the help of a trusted editor, I was compliant. I got great job satisfaction from my reports. Some of my consulting reports were admitted in court hearings. So I ask each documentation developer to actually do the hands-on effort, personally, and develop feedback for phase II utilization of the documentation, which can improve your compliance and basic cooperation. Great editors are also teachers who give feedback and develop skills important to your organization.

Documents that cannot be altered, revised, amended or documentation that can be changed, must be determined at the development stage. Our world of "do-overs" is almost expected by the populace. Legal versus informational purpose should be decided at the very beginning of the development. Most likely, the information within the document/report also has a legal implication. Those dreaded errors and omissions!

When I worked as a medical/legal researcher, I first set up a timeline. Did I go through boxes of documents and reports first? No, I went to the line item billing first. This always gave me a roadmap. I also discovered errors between billing and documented services and intervening circumstances within the reports. If it is not documented, did it happen? Billing or invoicing records what was done, and should show evidence of other professional reviews or opinions taken into account.

Line item billing sometimes can be used for unravelling the acronyms of the profession as well, so this was a time saver. For those running audits, review of the billing at the start can be a big timesaver, if applicable.

Actually providing the documentation takes time and experience. It is a skill learned and practiced. In my case management world, I have met Master-level educated case managers who cannot write, let alone document a full month of case management activity and interactions. Did they provide perfect case management? Yes, when speaking with them and looking at activity notes. No, when looking solely at their reports. Great documentation takes practice, openness to critique, 
education and a trust in the editor. Organizations develop skills that protect their organization and provide informational documentation to their customers. In my world experience is everything, skill is learned, and documentation keeps our licenses in good order.

I really appreciate when documenters ask or are receptive to suggestions, additions or revisions that make the report so valuable. Another set of eyes on the document (editor/reviewer) is, in my opinion, necessary to finalize the document before submission. Evidence-based, documentation as opposed to summation is my preference. Again, ask if the report will be relevant in 2-5 years? Does the document state what occurred to aid the professional in their decision making or activity? That is the purpose, after all, of documentation.

Taking time to document, taking proper notes, following the lines of proper grammar and writing, including proper citation, are activities not done distracted and not done well last minute. Valuebased documentation is integral to true professional case management and is the elusive competitive edge.

Document with thought, purpose and insight. You will have successfully recorded all your hard work. Should you ever need to review a decision 2-5 years later, you can revisit with confidence, who, what, when and where of your professional decision. 